Granville Stanley Hall, founder of the American Psychological Association and president of Clark University, was the first American psychologist to speak and write about music's place in the educational curriculum. An examination of his published writings reveals Hall based his theory of music education on principles of Social Darwinism and Child Study perspectives on education. Hall's theories are referenced and paraphrased in several song series textbooks and music appreciation texts published by music educators during his professional career. These sources indicate that Hall influenced the thinking of certain music educators and was important to music education, in general, in developing a receptivity toward psychological processes in music education practice.

R. R. Rideout, University of Oklahoma

\title{
On Early Applications of Psychology in Music Education
}

Granville Stanley Hall (1842-1924) received the first doctoral degree in psychology in the United States (from Harvard, in 1878). After a twoyear sojourn to Europe, where he studied the educational system of Germany, Hall returned to America where, in 1881, he was hired by Charles Elliott, president of Harvard University, to deliver a series of lectures on the state of education in Germany. He gave these lectures for teachers in the Boston environs (Ross, 1974, p. 133). In 1882, upon a recommendation from his former professor, William James, Hall was appointed professor of psychology at Johns Hopkins University. Among his students were John Dewey and James McKeen Cattel, both of whom became noted leaders in education in the first half of the twentieth century (Wilson, 1914). In 1888, because Jonas Clark was impressed with Hall's personality and work at Johns Hopkins, Hall became the first president of the university Clark was founding on the Johns Hopkins model (Ross, 1974, pp. 186-206).

During his long tenure as president of Clark University (1888-1920), Hall championed many causes in American education and psychology. He formed the American Psychological Association at his residence in

Requests for reprints should be sent to R. R. Rideout, School of Music, 560 Parrington Oval, Room 109A, University of Oklahoma, Norman 73109. 
Worcester, founded and edited the Journal of that organization as well as several other periodicals pertaining to psychological and pedagogical inquiry, and wrote and published on such controversial issues of the day as eugenics and the psychology of religion (Hall, 1911; 1922). As part of his efforts to further the development of psychology in America, he sponsored the first visit by Sigmund Freud to this country. At Clark University, Freud spoke on his theories of the subconscious before an assembly of psychologists, among whom were such notables as Carl Jung, William James, Joseph Jastrow, and Carl Seashore (Ross, 1974, p. $395 \mathrm{ff})$.

Ross (1974, pp. 62-102) discussed fully the Social Darwinist foundations of Hall's psychological theories. Hall defended recapitulation theory as the model for growth and development of the individual and agreed with Herbert Spencer and his followers that the development of entire cultures and civilations is founded on evloutionary principles. An important implication of these theories was that the mind of man still was evolving. Therefore, man and his society could be seen, not as finished products in full grasp of environment and self, but as imperfect beings still evolving. Hall $(1906,1914)$ postulated that empirical psychology would provide a scientific means for refining and improving human growth. These theories also implied that if man evolved through stages of development (phlogeny), then those stages were represented in the growth of each individual from infant to adult (ontogeny). If in the growth to maturity the child recapitulated the man's development, then his individual and social actions indicated a history of humanity's growth to maturity and reason. A chronology of mankind's societies, institutions, past, and future could be determined through close examination of the stages of child development.

To test such theories, an empirical investigation of the mind was needed. Philosophy with its introspective method did not serve that end efficiently; nor did physiology or anatomy, since neither studied man as an active, integrated being. A new method was needed that would allow for the study of man as a physical, mental, and spiritual whole. The new school of psychology was the answer. Dewey (1951, pp.1-19) noted that the term "new" was used to differentiate between supporters of Darwinian experimental psychology and the supporters of the old school of psychology based upon the epistomology of Immanuel Kant and Georg Hegel. Dewey explained that, in practice, those terms were used to distinguish means more than ends. The old school of psychology, built upon millenia of intellectual tradition, relied on logical reasoning and introspection as means of validating hypotheses. The new school of psychology tested hypotheses through controlled observation and empirical research. To proponents of the old, adherents to the new never would rise above physiology to the higher problems of nature of will, cognate functions, and human value (Harris, 1895). To proponents of the new, explanation of such problems would be found in environmental and biological conditioning and, to Hall at least, in evolutionary processes. The answers to the problems of the old school of psychology would be found in the laboratory through work in genetics and in the 
world through controlled observation of human development and human activity (Hall, 1911).

Although the limitations of the Social Darwinist theories were noted during Hall's lifetime (James, 1899), he remained a strong supporter of them, spending his entire career searching for evidence supporting his claims (Hall, 1923, p. 430). Hall sent questionnaires to thousands of persons asking for facts and opinions. The questions often were constructed to support his bias toward recapitulation theory, and the data were treated as finished products whose sum substantiated his position (Hall, 1923, p. 348ff).

Because of the unscientific procedures he used in gathering and analyzing psychological data (Thorndike, 1928, p. 141), succeeding generations of American psychologists rejected Halls's conclusions about mental processes. Hall's professional influence waned as his years advanced, and by his death he was viewed as a historic figure more influential in popularizing psychology than as one actively at the center of psychological development. Edward Thorndike (1928) wrote of him,

Hall was essentially a literary man rather than a man of science and artistic rather than a man of fact. . . It is true he used his extraordinary intellect and energy to discover facts and defend hypotheses...but he was not content with discovery alone or with the approval of a small body of experts....The truth he sought was preferably important, bearing directly upon great issues, pregnant with possibilities of evolution and revolution ( $p$. 144).

Hall is known best to educators for his heated debates with William Torey Harris, U. S. commissioner of education, and for his leadership in the Child Study movement. The debates with Harris, chronicled and examined by Burgess (1962) and Strickland (1963), developed from hall's continuing disagreement with Harris over the nature of the elementary school curriculum. Harris was a Hegelian who disliked Hall's Darwinist position. As a champion of traditional religious and philosophical values in American schools, Harris attacked all efforts by followers of Rousseau, Herbart, Froebel, Pestalozzi, and Spencer to alter the predominant strain in American education (Harris, 1898). To Harris, Hall's theories were part of reform efforts that led education astray from its true function-the development of the child's abstract reasoning (Harris, 1895).

Conventions of the National Education Association became the arena for their arguments over the old and new schools of psychology, and over the place of intellect and emotion in the development of the child (Harris, 1894, p. 863). Harris's influential position proved damning to Hall in the early 1880 s. Hall was unable to win many supporters to his position. Still, as the decade wore on, Harris's criticisms gave focus to the arguments between the old and new psychologies. Educators appeared to see Harris's position as a defense of the existing system and as repudiation of science as a foundation and means to effect social and educational change (Ross, 1974, pp. 130ff). His attempts to quell the tentative claims of Hall and child study research failed. Hall's call for an 
empirical psychology in education caught the attention of those who believed its time had come. Although many felt Hall's claims were extreme and premature (Thorndike, 1898, pp. 645-50), his basic concern for the emotional and physical welfare of the child captured the popular imagination, and his call for an empirical psychology captured the scientific imagination (Ross, 1974, pp. 365-6).

This national exposure, coupled with Hall's positions at Johns Hopkins and Clark, cast him in the forefront of educational reform. By 1900, he and his colleagues at Clark had formed the nucleus of child study research, offering lectures and seminars for teachers interested in learning about the growth and development of children that the new psychology was sure to define (Pruette, 1924). Fundamental to this effort was Hall's belief that teachers and schools were central to controllers of the growth and development of the child; Hall's lectures, however, spoke more of the potential for educational improvement that psychological information and processes would provide than of specific pedagogical practices to be deduced from the available information (Hall, 1907; 1908).

By World War I, Hall's child study efforts had been eclipsed by the progressive education writings of John Dewey. While hope of the new psychology forming a foundation for educational reform had been established, the realization of the goal of a completely empirically-based educational pedagogy seemed no closer to fruition than when Hall first had proposed it in the 1880s (Ross, 1974, p. 358ff). Due to the declining interest in his child study work after 1902, Hall no longer lectured on child study topics but instead devoted his attention to the psychological data being amassed from many questionnaires sent to parents and teachers throughout the country about the behavior of children (Ross, 1974, pp. 341-367). He presented this information in many books, culminating in the two-volume collection Educational Problems (Hall, 1911). This publication and several earlier lectures and articles provide the sources for Hall's theory of music education.

Within Hall's psychological theories, sound was the most primitive of mankind's contacts with self and environment. As mankind's first utterance, music provided the best access to and outlet from the individual's emotional world. It was a primal element in evolutionary history. In Hall's view, music was still a primal element in mankind's mental constitution, since the mind was the product and processor of such primal forces. Thus, music is an essential factor in the healthy development and training of mankind's emotions today (Hall, 1911, p. 93).

Hall believed that the emotions of the child were pliable and could be swayed to good or ill through exposure to the proper music. Therefore, a systematic and appropriate curriculum was necessary in the schools (Hall, 1907). Instrumental music was delayed until the higher grades, because it required knowledge of notation, which was an intellectual study inappropriate to the elementary grades. Vocal music was the preferred artistic vehicle of learning, and it first had to be presented aurally and learned through memorization. Rote singing had to precede 
note learning. Speaking against the drill approach to note reading, Hall (1911) said,

Few teachers seem to realize that singing is at first best learned by imitation, and a good collection of songs by rote should always come before all exercises, scales and intervals and long before note reading, which is [a] purely intellectual process. (p. 110)

Hall contended that music in most vocal music series did not contain sufficient musical content to inspire the child. Moreover, songs were not arranged with any concern for the child's natural interests or his or her stages of development. Hall insisted that all educational methods and practices be geared to the stages of child development he had derived from his research (Hall, 1907, pp. 13-17). Music teachers were a particular target of his lectures because many introduced technical knowledge such as scales and intervals before it was appropriate or presented rote songs of such insipid quality as to impair emotional growth in the child (Hall, 1911, p. 110).

Hall believed any method attempting an intellectual approach to music instruction at the elementary level was psychologically in error. Music's educational worth was in its ability to excite the emotions. Music common to the culture, such as patriotic songs and folksongs, were the preferred material with which the music teacher could inspire the child (Hall, 1911, p. 96).

Several authors of vocal series textbooks reflected Hall's theories of music education by using his child study rhetoric. Junkermann (1893), Holt (1893), Broekhoven (1896), Tilden (1898), Whiting (1911), and Johnson (1912), to list but a few, reflected some aspect of Hall's thought on music education. Even so, Hall's theories found fullest expression in the publication of the Progressive Music Series published by Silver Burdett in 1914-16. Written largely by Osbourne McConathy, this series was based solidly on the stages of child development defined by Hall and sought to establish a hierarchy of learning in light of child study research. McConathy, et al. (1914-1916), referenced Hall's works and paraphrased his child study philosophy in the preface of the series.

The aim of education is to train the child to become a capable, useful and contented member of society. The development of a fine character and the desire to be of service to humanity are the results that lie uppermost in the minds of leaders of educational thought. (p. 18)

The series capitalized on children's interests and abilities. The authors sought to control the pace of learning and the musical perceptions of the student by providing copious instructions to teachers about how to approach instruction at each stage of pupil development.

Hall was consulted several times during the preparation of the series and was pleased with the outcome. As he wrote in his review of the publication (1917),

With this formidably ponderous series... we have really an epoch-making step taken toward better conditions.... The kind of music it offers the child 
is properly stressed and is the best of any series yet made accessible to children. Thus, it marks a distinct and most wholesome epoch in music pedagogy. (p. 587)

At the secondary level, with the emergence of intellect in the adolescent, music's purpose expanded and the method of presenting music, as well as the values to be inculcated through the study of music, changed. Hall believed music drew on the fund of subconscious values, developed through years of rote singing, of the individual's character (1907, pp. $14-16 ; 1911$, pp. 96-123). This was achieved by a new and dramatically different musical experience. Hall (1911) called for a course of study in which the adolescent would be trained in an appreciation of all who preceded him in human history:

Music can express the soul of great men, epochs, events, races. These can live, move, and have their being in music, which is thus in some sense the very soul of history, especially culture history. It should be given this setting for children. The sentiment of the period and the personality of the author of "The Battle Hymn of the Republic," "Die Wacht am Rhein," "Rule Brittania," etc., should be made to glow in the juvenile soul beforehand by vividly and carefully prepared description and story. Musicians should be full of patriotic, not to say military, spirit. . (p. 96)

The effect of music education on the emerging adolescent intellect is explained in light of Hall's evolutionary theory. The regeneration of the emotional life, begun in elementary school, is refined to an appreciation of cultural history. This is achieved by combining the inspirational quality of music with a thorough technical knowledge of the history of music (1911, pp. 124-131). Although Hall's description reflected the content of traditional music appreciation courses that became a part of the secondary curriculum at that time, it would be incorrect to imply that Hall directly influenced the growth of music appreciation. Dunham (1961) showed that music appreciation developed primarily as the result of the decision by the National Education Association to give academic credit for music and the decision by the College Entrance Examination Board to add music to its exams. Whether these decisions and the resultant textbooks were prompted by the writings of Hall or by any of the child study research is not discussed by Dunham.

Several authors of music appreciation textbooks reflected Hall's concern for an appropriate secondary curriculum. Stone (1916) and Earhart (1905) were examples, yet neither of the authors credited Hall directly for any pedagogical or psychological foundation to their work.

One only can surmise that Hall's philosophy reinforced the direction established by Surette and Mason (1907) and Frances Clark (1902). Equally, the appreciation embodied his Darwinistic/recapitulatory theories on music teaching at the secondary level. The intent was to train intelligent and capable music listeners who understood and respected the cultural tradition of the Western world and its artistic products. 


\section{COMMENTARY}

With the addition of the appreciation course, Hall's music curriculum was complete. At the elementary level, instruction in rote singing led to musical experiences in which enjoyment and pleasure were the outcome for the individual, and instruction in moral and social values was the outcome for mankind. At the secondary level, the aesthetic experience combining knowledge with feeling was the outcome for the individual, while an understanding of the individual's social responsibility in light of cultural history was the outcome for mankind.

Hall (1907) summarized the value of music education for the individual in stating his goal for music instruction.

So my first plea is for more extensive musical culture, that almost all our academic youth learn to sing or play, or at the very least, be taught to know, love, and more intelligently appreciate good music in order to normalize and regenerate their emotional life, to make them feel country and nature in all her aspects, religion in all its breadth and depth, to sanify and idealize the affections. (p. 14)

Although Hall defended music at all levels of the educational curriculum, one may question much of his explanation of its function in the life of the individual. At the elementary level, music subconsciously conveys social values. Music intensifies their meaning by presenting them in a form both readily applealing and essential to mankind's mental evolution. At the secondary level, music reinforces cognitive learning about mankind's past through facts about composers, their works, and the culture in which they lived. Since the young child cannot reason, according to Hall's psychological theory, there is no intellectual value to music in the elementary curriculum. As intellectual processes develop in the adolescent, the outcome of music instruction is not explained in terms of musical knowledge and skills, but as appreciation for cultural heritage. Thus, music becomes a vehicle for the general education of the student. The musically-sensitive individual who appreciates music for its intrinsic value is secondary to the individual who understands cultural heritage and contemporary social and cultural values reflected in music. Music's personal function is to provide pleasure and an expression of common cultural heritage and experience.

This view is consistent with much of the literature of the day and partly explains Hall's declining influence in the decade before World War I. He appeared to many educators to use the popular rhetoric of instrumental ends while claiming an empirical psychological basis for same. Psychologists rejected his claim as did many educators. Yet, in certain ways, this misinterpreted Hall's work. Although he used his highly romantic and value-laden language to express theories familiar to educators, the ideas were inconsistent with the contemporary jargon of the day. In recapitulation theory and Social Darwinist thought, there was a reason to make claims for the emerging new psychology, thereby 
claiming such outcomes for music education. Biology under the Darwinians had set aside theories about the mind that had been the main topic of philosophical arguments for several hundred years. Scientists felt no responsibility to place the nature and function of the mind under scientific scrutiny. In their claim that man was a product of evolution, however, the implication remained that the mind was also a product of such forces. As Dewey (1951) noted, this implication required philosophers to discard much of the logical, introspective analysis of the mind that has preceded Darwin and to search for an empirical approach to analyze mental activity. The new psychology, in affirming that the mind was governed by biological forces and could be studied scientifically, once again placed the question of the nature and function of the mind in the midst of intellectual discussion but posed an additional problem. One could not establish the controlled conditions for experimentation without a working definition from which to formulate hypostheses. This problem led to a generation of discussion about the nature and function of the mind-not the least part of which was the discussion of attitudes, feelings, and human will.

Hall based his explanation of feelings on the behavior he expected an individual to exhibit when properly educated in the system the new psychology would define. He outlined such behaviors in terms readily recognizable in contemporary society, such as love of country, love of family, an enobled character, and a sentient heart. Such an explanation, although limited to the cultural and social perspective of Hall's own theories, served as a working definition for Hall in measuring the possible degree of learning afforded by any subject in the curriculum. Thus, one can interpret Hall's expression of music's effect in an individual's life as an attempt at defining in specific observable behaviors, that aspect of man's mind music stimulated. The regeneration of the emotional life and the wholesome development of the affections brought about by music ennobled mankind's character, which was expressed in deliberate actions. The specific actions, which he defined in instrumental terms, placed music more solidly in a measurable, empirical framework providing the basis for research that the new psychology demanded. In this interpretation, the goal of music education, and the specific human behaviors used to measure the attainment of that goal, would not appear in conflict. The humanistic end of regenerating the emotional life is reconciled to the specific social and moral values Hall outlined.

Since Hall was not an experimenter, the psychology he espoused did not reflect the more experimental approaches to music psychology associated first with Hemholtz and later with the generation of Carl Seashore, Jacob Kwalwasser, Peter Dykema, Arnold Gesell, Frances Ilg, and others. Hall succeeded nevertheless in promoting an interest and faith in psychological processes as means for verifying hypotheses and testing educational problems. He was the first to call music educators' attention to the pedagogical possibilities afforded by a union of music and the new psychology. He was the link between the experimental psychology of his colleagues and the practical problems of the classroom teacher. He championed a psychological foundation to educational activity and popularized his position through articles and lectures 
delivered to inspire faith and support among teachers. While obscurity befell him as a result of his personal psychological theories, the legacy he left of professional organizations, periodicals, and concern of an educational public for an empirical foundation to their work were unequalled in his lifetime. What Lawrence Cremin (1959) wrote of his work in general education seems appropriate to his efforts in behalf of music education:

For all his influence in his own time he is little celebrated today. Yet, it is this very influence that necessitates our remembering him; for he injected into the mainstream of American educational thought some of the most radical-and I happen to think virulent doctrines of the twentieth century, and there is no understanding the present apart from his contribution. (Preface)

\section{REFERENCES}

Broekhoven, J. \& Gantvoort, A. J. Model music course for schools. Cincinatti: John Church, 1896.

Burgess, C. S. The educational state in America: Selected views on learning as the key to Utopia, 1800-1924. Unpublished doctoral dissertation, University of Wisconsin, 1962.

Clark, F. E. High school music. Proceedings of the Music Supervisor's National Conference, 1902, 626-633.

Cremin, L. Preface. In C. Burgess \& C. Strickland (Eds.), Health, growth, heredity: Selected writings of G. Stanley Hall. New York: Columbia University Press, 1959.

Dewey, J. The influence of Darwin upon philosophy. New York: Peter Smith, 1951.

Dunham, R. Music appreciation in the public schools in the United States, 18971930. Unpublished doctoral dissertation, University of Michigan, 1961.

Earhart, W. The critical study of music in the high school. School Music, JanuaryFebruary, 1903, 11-15.

Hall, G. S. Eugenics, its ideals and what it's going to do. Religious Education, June 1911, 152-159. (a)

Hall, G. S. Youth: Its education, regimen, and hygiene (2 vols.). New York: D. Appleton, 1898.

Hall, G. S. The function of music in the college curriculum. Proceedings of the Music Teachers National Association, 1907, 13-24.

Hall, G. S. The pedagogy of music. In Educational Problems (2 vols.). New York: D. Appleton, 1911, 91-113. (b)

Hall, G. S. The psychology of music and the light it throws on musical education. Pedagogical Seminary, 1917, V. 24, 587.

Hall, G. S. Salvaging civilization. Century, October, 1922, 830-840.

Hall, G. S. Life and confessions of a psychologist. New York: D. Appleton, 1923.

Harris, W. T. The difference between efficient and final causes in controlling human freedom. Washington, D.C.: National Education Association, 1895.

Holt, H. New and improved normal music course. Boston: J. Frank Giles, 1893.

James, W. Talks to teachers about psychology. New York: Henry Holt, 1899.

Johnson, A. E., \& Loomis, H. W. Lyric music series. New York: Silver Burdette, 1914-1916.

Pruette, L. G. Stanley Hall: Biography of a mind. New York: D. Appleton, 1924.

Ross, D. G. Stanley Hall: The psychologist as prophet. Chicago: University of Chicago Press, 1974.

Stone, K. Outline for music appreciation for the elementary schools. Los Angeles: County Schools, 1916. 
Strickland, C. The child and the race, the doctrines of recapitulation and cultural epochs and the rise of the child study ideal in American educational thought. Unpublished doctoral dissertation, University of Wisconsin, 1963.

Surette, T. W. \& Mason, D. G. The appreciation of music. New York: H. W. Grey, 1907.

Tilden, W. S. Handbook of lessons. Boston: Ginn and Co., 1889.

Thorndike, E. L. Assessment of G. Stanley Hall. Biographical Memoirs \#12 (National Academy of Sciences, 1928), $141 \mathrm{ff}$.

Whiting, C. New public school music course. Boston: D. C. Heath and Co., 1911. Wilson, L. N. G. Stanley Hall: A sketch. New York: G. E. Stechert, 1914.

November 16, 1981 